\title{
Wind Direction Estimates from Synthetic Aperture Radar Imagery of the Sea Surface
}

\author{
Todd D. Sikora \\ Millersville University \\ P.O. Box 1002 \\ Millersville, PA 17551-0302 \\ phone: (717) 872-3289 fax: (717) 871-4725 email: Todd.Sikora@millersville.edu \\ George S. Young \\ The Pennsylvania State University \\ 503 Walker Building \\ University Park, PA 16803 \\ phone: (814) 863-4228 fax: (814) 865-3663 email: young@meteo.psu.edu \\ Grant Numbers: N00014-06-10046 (Sikora) and N00014-04-10539 (Young)
}

\section{LONG-TERM GOALS}

Our long-term goal is to employ synthetic aperture radar (SAR) imagery of the sea surface as a marine meteorological research and forecasting tool. That is, we aim to use SAR to discover dynamical and morphological characteristics of microscale, mesoscale, and synoptic scale marine meteorological phenomena. We also aim to demonstrate how the fruits of our discovery can be used to aid marine meteorological analysts and forecasters.

\section{OBJECTIVES}

1. Investigate the range of near-surface mean wind directions with respect to the orientation of common microscale and mesoscale quasi-two dimensional phenomena seen in SAR imagery of the sea surface.

a. Provide empirically-derived guidelines on how to distinguish the SAR-signature of one feature from another (see Figure 1 for examples of quasi-two dimensional phenomena seen in SAR imagery of the sea surface).

i. The quasi-two dimensional microscale and mesoscale phenomena that we are studying are wind shear-driven and terrain-driven gravity waves, convective roll vortices, gap flows, and island wakes.

2. Provide quantitative analysis of the impact of position errors in numerical weather prediction (NWP) model synoptic scale and mesoscale cyclones, anticyclones, fronts, and col regions on the wind direction-dependent retrieval of wind speed from SAR via CMOD-4.

a. Use the results of this error analysis to develop automated and semi-automated detection and morphing correction algorithms for displaced synoptic scale and mesoscale features. 


\section{Report Documentation Page}

Form Approved

OMB No. 0704-0188

Public reporting burden for the collection of information is estimated to average 1 hour per response, including the time for reviewing instructions, searching existing data sources, gathering and maintaining the data needed, and completing and reviewing the collection of information. Send comments regarding this burden estimate or any other aspect of this collection of information,

including suggestions for reducing this burden, to Washington Headquarters Services, Directorate for Information Operations and Reports, 1215 Jefferson Davis Highway, Suite 1204, Arlington

VA 22202-4302. Respondents should be aware that notwithstanding any other provision of law, no person shall be subject to a penalty for failing to comply with a collection of information if it

does not display a currently valid OMB control number.

1. REPORT DATE

30 SEP 2006

4. TITLE AND SUBTITLE

Wind Direction Estimates from Synthetic Aperture Radar Imagery of the Sea Surface

6. $\operatorname{AUTHOR}(\mathrm{S})$

7. PERFORMING ORGANIZATION NAME(S) AND ADDRESS(ES)

Millersville University,P.O. Box 1002,Millersville,PA,17551-0302

9. SPONSORING/MONITORING AGENCY NAME(S) AND ADDRESS(ES)

12. DISTRIBUTION/AVAILABILITY STATEMENT

Approved for public release; distribution unlimited

13. SUPPLEMENTARY NOTES

14. ABSTRACT

15. SUBJECT TERMS

16. SECURITY CLASSIFICATION OF:

a. REPORT

unclassified b. ABSTRACT

unclassified c. THIS PAGE

unclassified
17. LIMITATION OF ABSTRACT

Same as Report (SAR)
3. DATES COVERED

00-00-2006 to 00-00-2006

5a. CONTRACT NUMBER

5b. GRANT NUMBER

5c. PROGRAM ELEMENT NUMBER

5d. PROJECT NUMBER

5e. TASK NUMBER

5f. WORK UNIT NUMBER

8. PERFORMING ORGANIZATION REPORT NUMBER

10. SPONSOR/MONITOR'S ACRONYM(S)

11. SPONSOR/MONITOR'S REPORT NUMBER(S) 
i. Develop manual editor algorithm to correct for the case of important synoptic scale and mesoscale features missing or erroneously included in the NWP model wind direction field. See Figure 2.

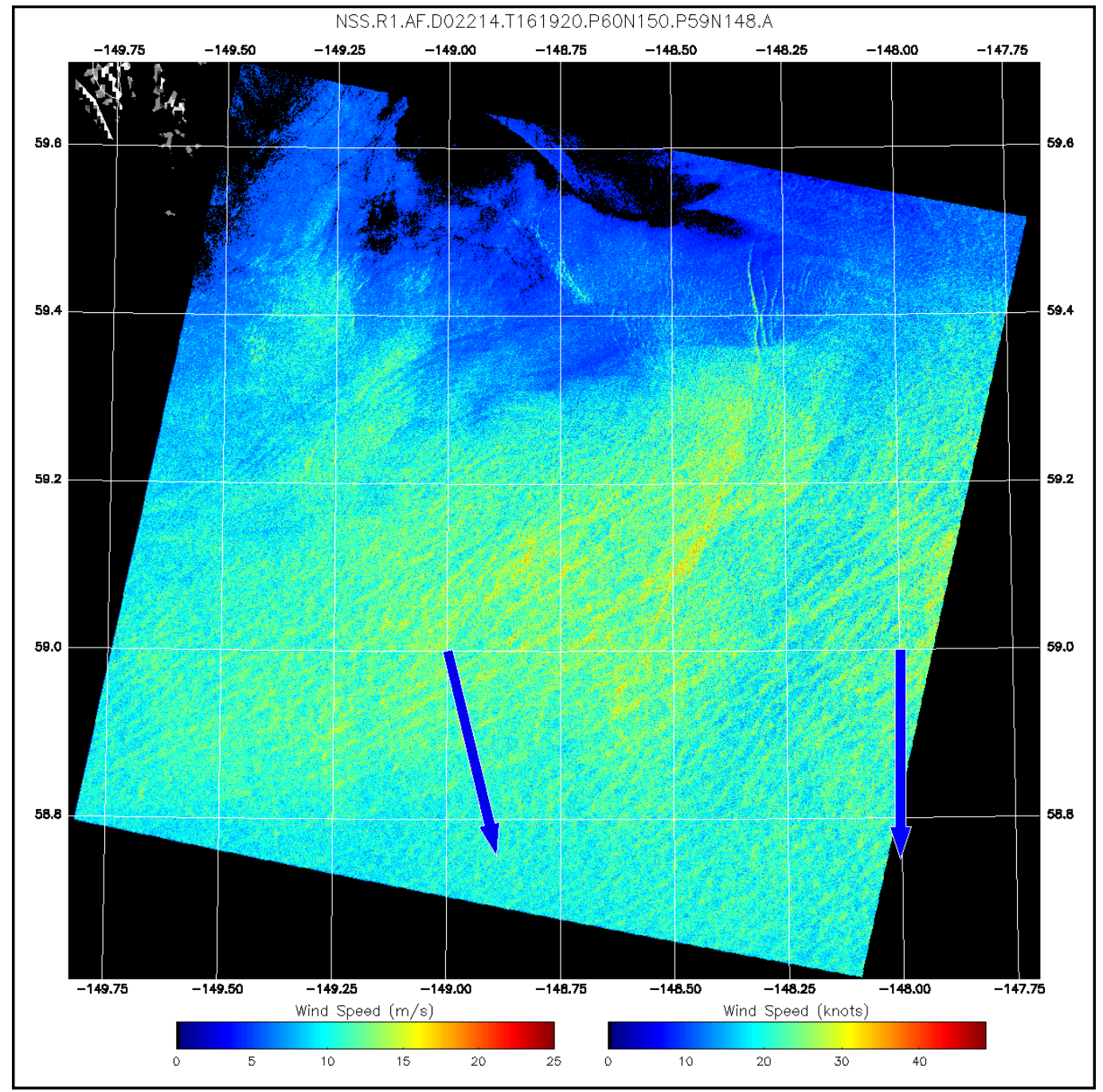

Figure 1. Radarsat-1 SAR-derived wind speed image. The corresponding SAR image was acquired at 16:19 UTC on August 2, 2002. The SAR-signature of convective roll vortices can be seen throughout the bottom portion of the image. Given the orientation of the roll vortices, the expected near-surface wind direction is from northeast. In contrast, the blue arrows are the wind directions provided by NOGAPS. (Data provided courtesy of Johns Hopkins University Applied Physics Laboratory (JHUAPL))

\section{APPROACH}

The basis of our research is SAR-derived wind speed imagery provided to us by the JHUAPL Ocean Remote Sensing Group. JHUAPL has an archive of over 30,000 SAR-derived wind speed images, mainly within the Alaska SAR Facility station mask. Most of these images are from the Canadian Space Agency's Radarsat-1 (C-band, HH polarization). 

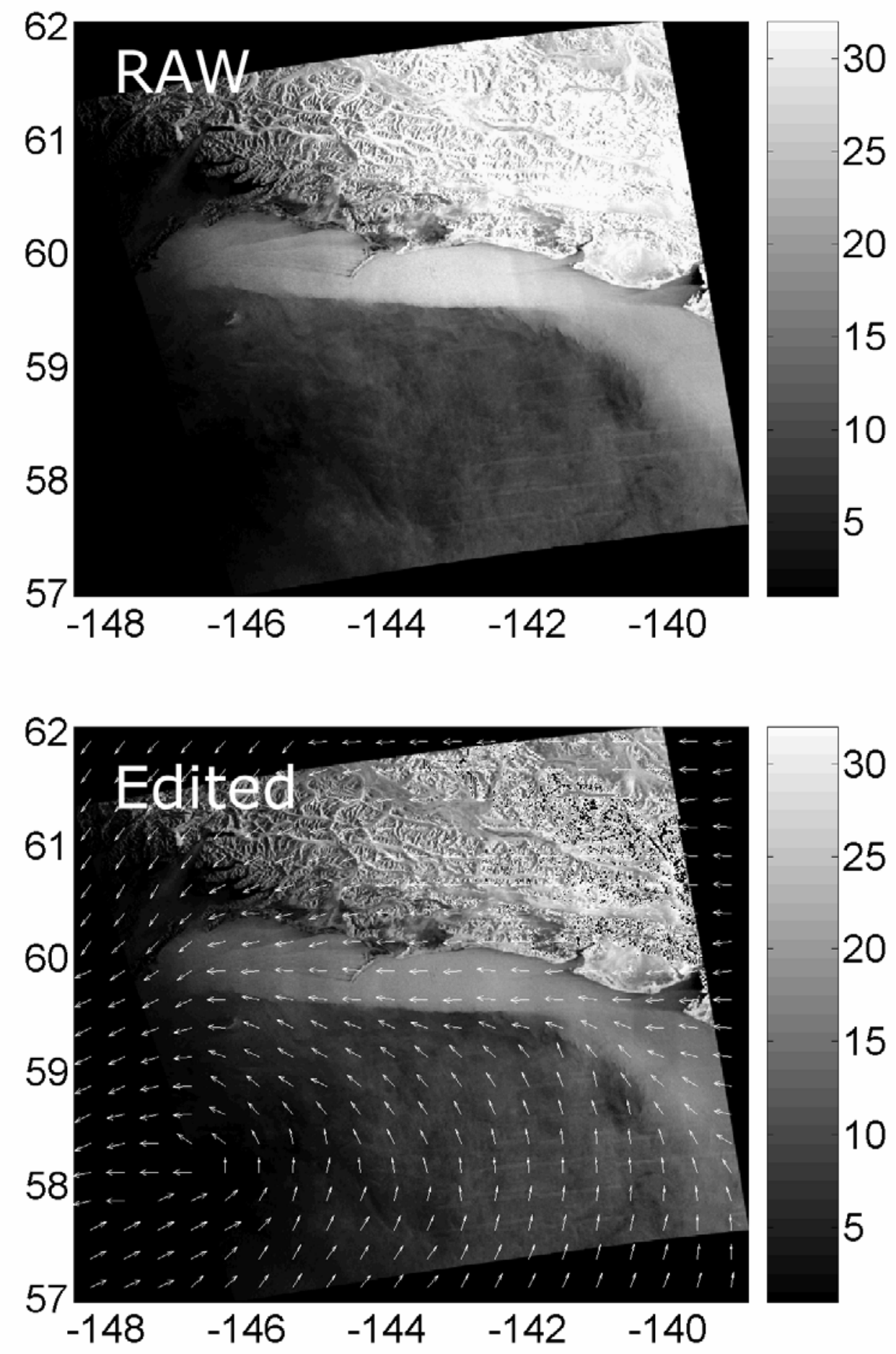

Figure 2. Radarsat-1 SAR-derived wind speed images. The corresponding SAR image was acquired at 3:10 UTC on February 18, 2000. The SAR-signature of a coastal barrier jet can be seen extending east-west through the center portion of the images. Manual editing of the NOGAPS wind directions based on SAR signatures and QuikSCAT observations significantly changed the analyzed wind speed (m/s) within the jet. Compare the "Raw" image to the "Edited" image. (Data provided courtesy of JHUAPL) 
MODIS full color satellite imagery is used to analyze linear cloud features not found within the Alaska SAR facility station mask.

Using National Centers for Environmental Prediction / National Center for Atmospheric Research (NCEP / NCAR) reanalysis data, we will assess the relationship between feature orientation and the near-surface mean wind direction.

Matlab is employed to create our methods for correcting NWP model wind direction errors to obtain a revised wind direction field suitable for use in SAR-derived wind speed retrieval.

\section{WORK COMPLETED}

In conjunction with our first objective, we are nearing completion of a SAR-feature climatology based on the JHAUPL archive (1998 - present). The current state of this research has been presented to the Summer 2006 National Oceanic and Atmospheric Administration (NOAA) Sea Surface Roughness Science Team Workshop.

In conjunction with our first objective, we have discovered a new form of quasi-two dimensional boundary layer circulations which we call dendritic convection. These branching roll circulations form in the presence of cold advection over tropical oceans when the wind speed is less than that required for buoyantly-driven roll vortices. The orientation of the resulting convective lines provides information on both the surface wind direction and the boundary layer wind shear vector. The corresponding refereed journal article is in press and the work has been presented at the $14^{\text {th }}$ Conference on Interaction of the Sea and Atmosphere where it won the student poster paper award.

In conjunction with our second objective, we have completed a climatology of the error signatures seen in SAR wind speed imagery as a function of errors from NWP-modeled fronts, cyclones, anticyclones, and col regions. Matlab code was developed to recognize these signatures and to execute manual and automated single-control-point morphing of cyclone, anticyclone, and col region positions and manual multi-control-point morphing of frontal positions. In addition, Matlab code was developed to enable manual editing of the input wind direction field for the case of synoptic scale and mesoscale features missing from the NWP model wind direction field. A corresponding journal article is currently in review.

In conjunction with our second objective, a follow-on study is underway that is focused on distinguishing between oceanic and atmospheric fronts in SAR imagery. The follow-on study is being conducted by Werner Alpers, Jochen Horstmann, Andrei Ivanov, Leonid Mitnik, and Todd Sikora. A corresponding conference paper has been presented and journal article is being prepared.

\section{RESULTS}

We have developed a SAR-based microscale and mesoscale feature climatology in order to provide information about the surface wind direction and lower tropospheric wind shear direction. Analysis of 9 years of JHUAPL's SAR-derived wind speed, yielding annual frequency distributions for the region surrounding Alaska, is nearing completion. Features studied include: wind shear and terrain driven gravity waves, microscale and mesoscale cellular convection, convective roll vortices, gap flows, and island wakes. Boundary layer winds align nearly parallel to most types of roll vortices, gap flows, and island wakes. In contrast, terrain driven waves form patterns perpendicular to the mountain-top winds, 
while wind shear driven gravity waves align perpendicular to the wind shear across the lowest inversion layer (i.e. the thermal wind resulting from the tilt of that inversion). Gust pattern orientation in cellular convection depends upon both wind and wind shear directions. Research is continuing on the more complicated of these relationships.

An observational analysis of the structure and synoptic setting of tropical dendritic cumulus formations was completed using 30 months of visible imagery from the MODIS Terra and Aqua satellites, surface winds from QuikSCAT, and the wind shear and stability profiles from the NCEP / NCAR reanalysis data. This analysis yielded 1,216 cases of tropical dendritic cumulus formations of which 61 were randomly selected for quantitative study. From these sample cases, it was found that dendritic patterns in shallow cumulus occurred over warm tropical oceans in response to cold air advection. Moreover, shallow cumulus formations take on a dendritic pattern only when the background wind velocity is between $1.5 \mathrm{~ms}^{-1}$ and $13 \mathrm{~ms}^{-1}$ in the surface to $850 \mathrm{hPa}$ layer and a shallow layer of conditional instability is present. Individual cumulus clouds in these dendritic formations are arranged in a compound branching pattern in which each element of the pattern takes the form of a Y-shaped cloud line as shown in Figure 3. Analysis of the cloud pattern observations in conjunction with the scatterometer-derived surface winds and the lower tropospheric wind profiles from reanalysis data revealed that the individual $\mathrm{Y}$-elements are aligned closely with the surface wind direction, as linear cloud streets would be. These Y-elements are oriented so that their forked end aligns as closely as possible with the surface to $850 \mathrm{hPa}$ wind shear vector, even when this conflicts with the surface wind direction.

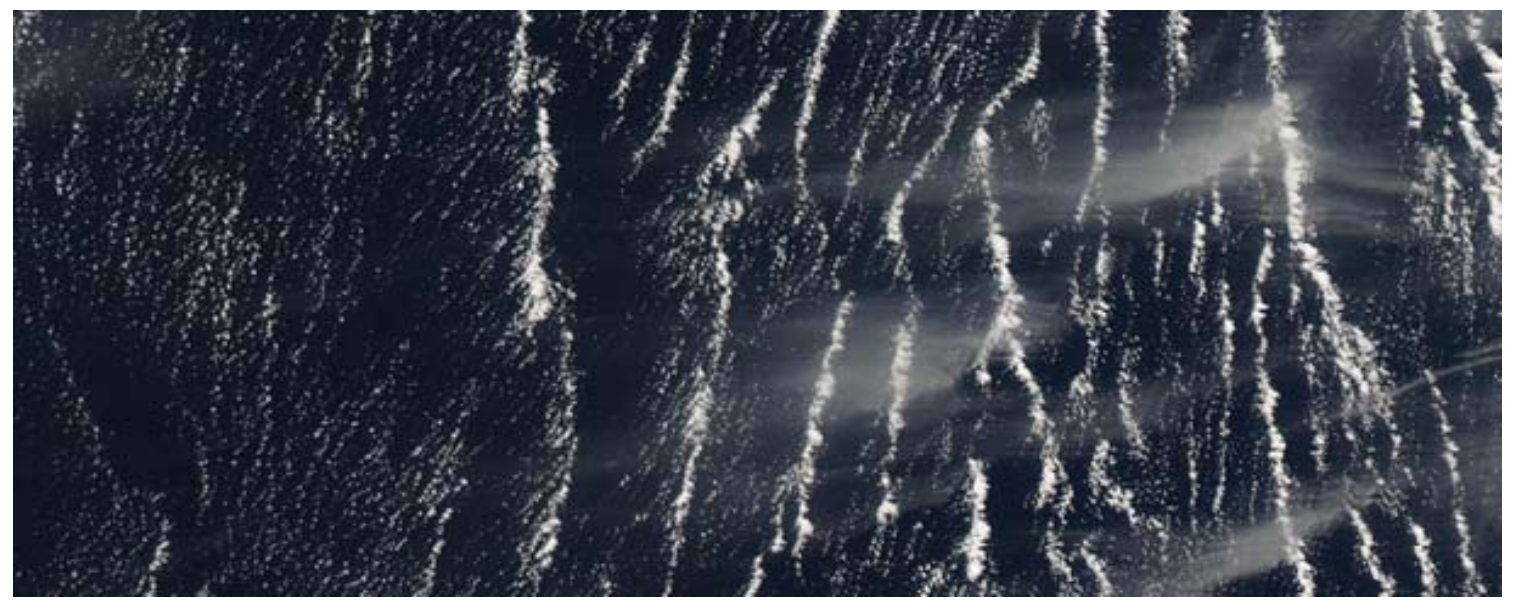

\section{Figure 3. MODIS image of a tropical dendritic cumulus formation embedded in a field of fair- weather cumulus over the western Indian Ocean at 955 UTC on September 28, 2004. Surface to $850 \mathrm{hPa}$ wind shear vector is directed from the top of the image to the bottom.}

Previous studies have demonstrated SAR wind speed generation is only possible only if an accurate wind direction field is available. The potential sources for wind direction include satellite scatterometers, NWP models, and SAR itself through analysis of the spatial patterns caused by boundary-layer wind structures as described in the preceding paragraphs. Each of these wind direction sources has shortcomings that can lead to wind speed errors in the SAR-derived wind speed field. Manual and semi-automated methods were developed for identifying and correcting NWP model wind direction errors. The utility of this approach was demonstrated using a set of cases in which the 
first-guess wind direction data did not adequately portray the features seen in the SAR imagery. These situations included poorly resolved mesoscale phenomena and misplaced synoptic scale phenomena. Figure 4 shows the bright band signature of a frontal position error and the corrected SAR wind speed field that results from manually morphing the NWP model wind field to correct the frontal position.
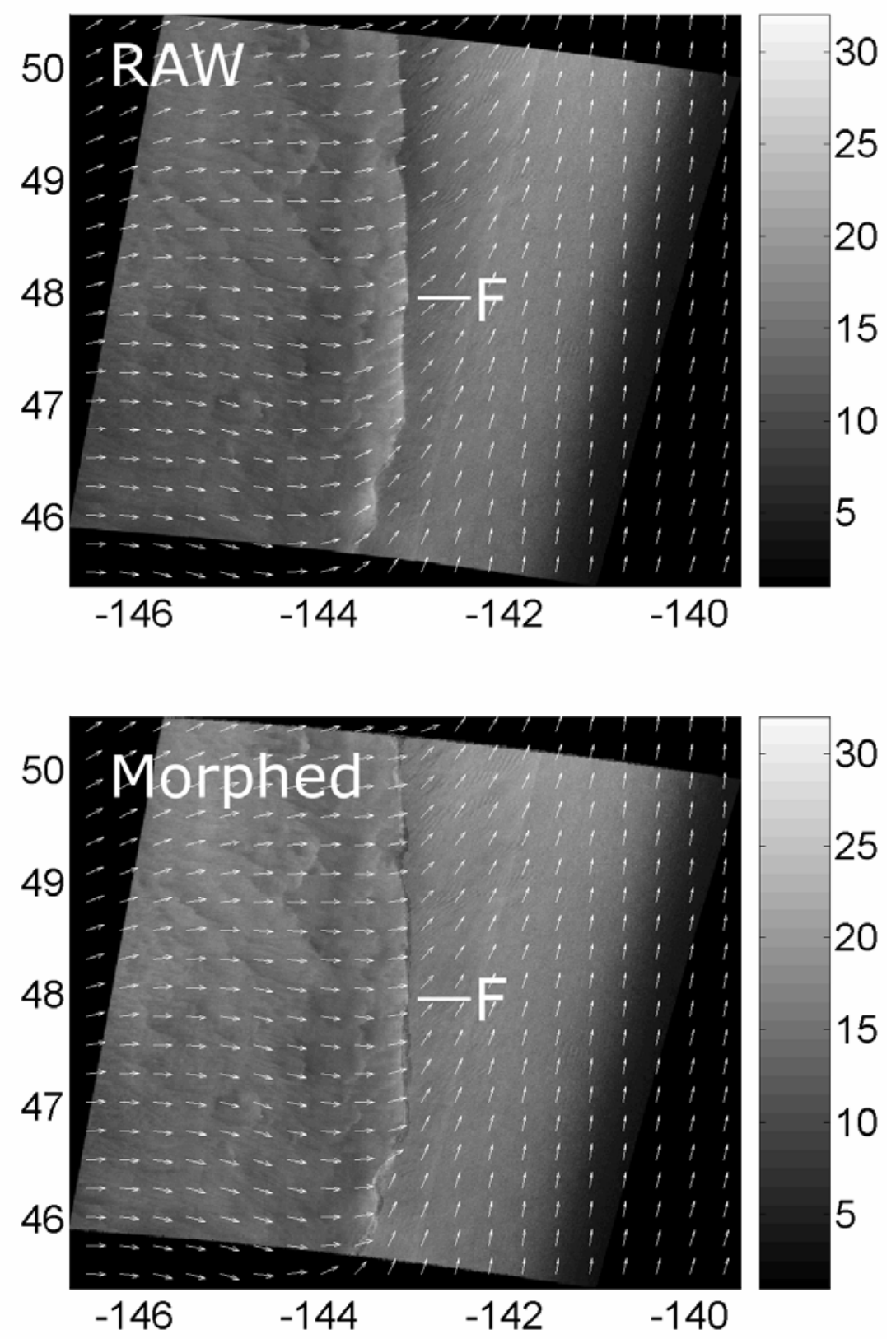

Figure 4. Radarsat-1 SAR-derived wind speed field for a cold front (extending north-south through the center of the image) in the Gulf of Alaska. The corresponding $S A R$ wind speed $(\mathrm{m} / \mathrm{s})$ image was acquired at 1545 UTC on 20 December 2001. The "RAW" panel shows SAR-derived wind speed field with the bright-band signature of a misplaced front in the first-guess wind direction field, marked $F$. The "Morphed" panel shows the re-derived after manually morphing the wind direction field to correct this position error and sharpen the frontal gradient. (Data provided courtesy of JHUAPL) 


\section{IMPACT/APPLICATIONS}

The research described herein fulfills ONR objectives by working towards the integration of meteorological theory and synthetic aperture radar data with the goal of providing high-resolution remotely sensed estimates of near-surface wind field in in situ data-sparse regions over the ocean, including the coastal zone. For example, the morphing software we've developed will allow users to obtain accurate SAR-derived wind speeds even when NWP model analyses used for the wind direction field have position errors for key synoptic scale and mesoscale features. Likewise, the linear featurewind direction research we are conducting will allow for more accurate SAR-derived wind speeds when users rely on the orientation of those linear features to deduce the input wind direction.

\section{RELATED PROJECTS}

George Young has an NSF-funded SAR project that supports the development of analysis tools essential to our ONR-funded research. The Matlab CMOD-4 code was developed jointly with NSFco-PI Nathaniel Winstead. An interactive SAR wind field analysis program with a graphical user interface was developed by George Young as part of this project and will serve as the host application for the automated and interactive wind-direction field morphing routines developed under ONR funding.

Todd Sikora is collaborating with Werner Alpers, Jochen Horstmann, Andrei Ivanov, and Leonid Mitnik, on a study focused on distinguishing between oceanic and atmospheric fronts in SAR imagery.

Todd Sikora is collaborating with Nathaniel Winstead and Carl Dierking on a NOAA-funded project to study the meteorological uses of SAR in the small inlets and mountain gaps that riddle the southeast coast of Alaska. The project goal is to determine the accuracy of SAR gap flow wind speeds under various synoptic scale situations (i.e., develop an error climatology) and to assess the impact of improved wind directions in these critical locations.

\section{PUBLICATIONS}

Young, G. S., T. D. Sikora, and N. S. Winstead: Manual and semi-automated wind direction editing for use in the generation of synthetic aperture radar wind speed imagery. J. Appl. Meteorol. [submitted, refereed]

Nicholls, S. D., and G. S. Young: Dendritic patterns in tropical cumulus: An observational analysis. Mon. Wea. Rev. [in press, refereed]

Sikora, T. D., G. S. Young and N. S. Winstead, 2006: A novel approach to marine wind speed assessment using synthetic aperture radar. Wea. Forecasting, 21, 109-115. [published, refereed]

Sikora, T. D., G. S. Young, R. C. Beal, F. M. Monaldo, and P. W. Vachon, 2006: Applications of synthetic aperture radar in marine meteorology. Atmosphere Ocean Interactions - Volume 2, W. Perrie, Ed., WIT Press, 83-105. [published, refereed] 
Alpers, W. R., Sikora, T. D., Ivanov, A., Horstmann, J., Mitnik, L. M., 2006: On the discrimination between oceanic and atmospheric fronts on SAR images of the sea surface. Proceedings, International Geoscience and Remote Sensing Symposium 2006, IEEE, Denver, CO, 31 July 4 August 2006. [published]

Sikora, T. D., G. S. Young and N. S. Winstead, 2006: A novel approach to wind speed analysis using synthetic aperture radar. Preprints, Fourteenth Conference on Interaction of the Sea and Atmosphere, AMS, Atlanta, GA, 30 January - 2 February 2006, CD publication. [published]

Young, G. S., N. S. Winstead, F. M. Monaldo, D. R. Thompson, and T. D. Sikora, 2006: Synthetic aperture radar observations of mesoscale atmospheric phenomena. Preprints, Fourteenth Conference on Interaction of the Sea and Atmosphere, AMS, Atlanta, GA, 30 January - 2 February 2006, CD publication. [published]

Nicholls, S. D., and G. S. Young: 2006: Tropical dendritic cumulus: An observational analysis. Proceedings of 14th Conference on Interaction of the Sea and Atmosphere, AMS, Atlanta, GA, 30 January - 2 February 2006, CD publication. [published] 